\section{AB0299 \\ THE INCIDENCE RATE AND THE MANAGEMENT OF EARLY RHEUMATOID ARTHRITIS IN A SINGLE CENTRE INTERVENTIONAL CLINIC}

R. Ješe ${ }^{1}$, K. Perdan Pirkmajer ${ }^{1}$, A. Ambrožičč ${ }^{1}$, N. Gašperšič ${ }^{1}$, A. Hočevar ${ }^{2}$ B. Lestan ${ }^{1}$, S. Markez 1 , M. Pavić Nikolić ${ }^{1}$, M. Plešivčnik Novljan ${ }^{1}$, S. Praprotnik ${ }^{1}$, Ž. Rotar ${ }^{1}$, A. Šipek Dolničar ${ }^{1}$, D. Šuput Skvarča ${ }^{1}$, M. Tomšič ${ }^{1} .{ }^{1}$ Department of Rheumatology, ${ }^{2}$ University Medical Centre Ljubljana, Ljubljana, Slovenia

Background: In patients with rheumatoid arthritis (RA), early diagnosis and adherence to the treat to target recommendations (T2T) limit RA progression and improve patients' quality of life. ${ }^{1}$ However, the implementation of T2T has always been a challenge, and real-life data are lacking. Slovenia has $40 \%$ less rheumatologists per capita than the European Union average, which makes the implementation of management guidelines even more challenging

Objectives: To determine the incidence of RA and the proportion of patients with incident RA in whom first rheumatology assessment was done within the recommended time frame.

Methods: We analysed the prospectively collected data of adult patients diagnosed with RA during years 2014 to 2016 at the Rheumatology Department of the University Medical Centre Ljubljana, Slovenia. The department provides rheumatology services to a well-defined region with a population of 704.000 adult residents. Dates were recorded for inflammatory joint symptom onset, referral to rheumatologist, first rheumatologic assessment and initiation of DMARD therapy. The percentage of patients assessed by a rheumatologist and/or treated with a DMARD within 12 weeks of symptom onset and the median times for delay were then calculated.

Results: Between 1 January 2014 and 31 December 2016, 341 incident cases of RA (75\% females, median age 61.9 (IQR 52-75.4) years) were identified, resulting in an annual incidence rate of $16 / 100.000$ population (in females: $23.6 /$ 100.000 ; in males $8.3 / 100.000)$. Most patients $(78.6 \%)$ were referred to our early interventional clinic. The median time from symptom onset to consultation was 12.9 (IQR 4.4-26.1) weeks, median time from referral to consultation was 1 (IQR 1-3) day. Median DMARD treatment delay was 16.6 (IQR 8.9-33.3) weeks. Within 12 weeks of symptom onset, $161(47.2 \%)$ new RA patients were examined by a rheumatologist and $123(36.1 \%)$ were started on DMARD therapy.

Conclusions: Our prospective data support the recent reports that uncovered a decrease in RA incidence. ${ }^{2}$ Moreover, despite the lack of rheumatologists and the heavily protracted nationwide waiting times for first rheumatologist assessment, our early interventional clinic enables us to recognise and manage substantial percentage of RA patients within the recommended time frame.

\section{REFERENCES:}

[1] Monti S, et al. Rheumatoid arthritis treatment: the earlier the better to prevent joint damage. RMD Open 2015;1(Suppl 1):e000057. doi:10.1136/ rmdopen-2015-000057

[2] Abhishek, et al. Rheumatoid arthritis is getting less frequent-results of a nationwide population-based cohort study. Rheumatology 2017;56:36$744-7$.

Disclosure of Interest: None declared

DOI: 10.1136/annrheumdis-2018-eular.2899

\section{AB0300 ULTRASOUND EVALUATION OF ANKLE AND FOOT JOINTS IN RHEUMATOID ARTHRITIS}

S. Fellous ${ }^{1}$, H. Rkain ${ }^{1}$, S. afilal ${ }^{1}$, L. Tahiri ${ }^{1}$, N. Alami ${ }^{1}$, R. Guieu ${ }^{2}$, J. yves ${ }^{2}$, F. Allali ${ }^{3}$, N. Hajjaj-Hassouni ${ }^{4}{ }^{1}$ Department of Rheumatology B, El Ayachi Hospital, Faculty of Medicine and Pharmacy of Rabat, Mohammed V University, Rabat, Morocco., Rabat, Morocco; ${ }^{2}$ UMR MD2 Faculty of Medicine, Aix-Marseille University, Marseille, France., marseille, France; ${ }^{3}$ Faculty of Medicine and Pharmacy of Rabat, Mohammed V University, Rabat, Morocco., Rabat, ${ }^{4}$ Center for Pedagogical Innovation, Mohammed VI University of Health Sciences, Casablanca, Morocco., casablanca, Morocco

Background: The foot and the forefootin particular are often one of the first areas to be affected by rheumatoid arthritis. The joint destruction develops not only as a result of synovitis but also as a result of specific biomechanical stresses leading to deformity

Objectives: Evaluate the prevalence of ultrasound signs of rheumatoid arthritis in the joints of the ankle and foot.

Methods: This is a cross-sectional study that included 14 consecutive patients ( $100 \%$ female, mean age 55.3 years) with rheumatoid arthritis (median duration of progression of 13.5 years, mean specialised care of 2.1 years). A grey and Doppler ultrasound study was performed by looking for effusions, synovitis, Doppler activity and bone erosions in the joints of the ankle and foot.

Results: 28 feet were studied with an ultrasound evaluation of 308 joints.

The prevalence of ultrasound signs of RA are shown in table 1 and 2 .
Abstract AB0300 - Table 1. Prevalence of ultrasound signs of RA in the forefoot $(\mathrm{N}=28)$

\begin{tabular}{lccccc}
\hline Echographic signs & \multicolumn{5}{c}{ Forefoot } \\
\cline { 2 - 6 } & MTP1 $\mathrm{n}=28$ & MTP2 $\mathrm{n}=28$ & MTP3 $\mathrm{n}=28$ & MTP4 $\mathrm{n}=28$ & MTP5 $\mathrm{n}=28$ \\
\hline Synovitis & 57.1 & 28.6 & 14.3 & 21.4 & 25 \\
Doppler & 0 & 0 & 3.6 & 3.6 & 3.6 \\
Effusion & 25 & 21.4 & 10.7 & 10.7 & 7.1 \\
Erosions & 67.9 & 3.6 & 10.7 & 17.9 & 7.1 \\
Osteophytes & 57.1 & 17.9 & 14.3 & 25 & 25 \\
\hline
\end{tabular}

Abstract AB0300 - Table 2. Prevalence of ultrasound signs of RA in the ankle and foot $(\mathrm{N}=28)$

\begin{tabular}{|l|l|l|l|l|l|l|}
\hline Echographic & \multirow{2}{*}{$\begin{array}{l}\text { Ankle } \\
\text { signs }\end{array}$} & $\begin{array}{l}\text { Talocrural } \\
\mathrm{N}=28\end{array}$ & $\begin{array}{l}\text { Subtalar } \\
\mathrm{N}=28\end{array}$ & \multicolumn{4}{|l|}{} \\
\cline { 5 - 8 } & & & $\begin{array}{l}\text { Talo-navicular } \\
\mathrm{N}=28\end{array}$ & $\begin{array}{l}\text { Calcaneo- } \\
\text { cuboid } \\
\mathrm{N}=28\end{array}$ & $\begin{array}{l}\text { Cubo- } \\
\text { metatarsal } \\
\mathrm{N}=28\end{array}$ & $\begin{array}{l}\text { Cuneo- } \\
\text { metatarsal } \\
\mathrm{N}=28\end{array}$ \\
\hline Synovitis & 60.7 & 50 & 46.4 & 7.1 & 7.1 & 3.6 \\
\hline Doppler & 0 & 0 & 0 & 3.6 & 0 & 0 \\
\hline Effusion & 39.3 & 25 & 10.7 & 7.1 & 0 & 10.7 \\
\hline Erosion & 10.7 & 10.7 & 0 & 14.3 & 14.3 & 3.6 \\
\hline Osteophyte & 28.6 & 39.3 & 71.4 & 39.3 & 42.9 & 14.3 \\
\hline
\end{tabular}

Conclusions: This study describes the various ultrasound signs at the joints of the ankle and foot. There is a high prevalence of synovitis in the ankle and hindfoot. Doppler activity has been rarely found.

A large-scale study compared with a control group is necessary to better interpret and complete these preliminary results.

Disclosure of Interest: None declared

DOI: 10.1136/annrheumdis-2018-eular.6693

\section{AB0301 SERUM PYRIDINOLINE IS ASSOCIATED WITH RADIOGRAPHIC JOINT EROSIONS IN RHEUMATOID ARTHRITIS}

S. Rajalingham ${ }^{1}$, A.M.M. Nor Hashimah ${ }^{1}$, S.S. Shaharir ${ }^{1}$, R. Sridharan ${ }^{2}$, A. Abdul Wahab ${ }^{3}$. ${ }^{7}$ Medicine; ${ }^{2}$ Radiology; ${ }^{3}$ Microbiology, Universiti Kebangsaan Malaysia, Kuala Lumpur, Malaysia

Background: Pyridinoline (Pyd) is a 3-hydroxypyridinium derivative which is an intermolecular cross-link compound of type I and II collagen. ${ }^{1}$ It is a marker of bone resorption based on bone biopsy and radioisotope kinetics studies. ${ }^{2}$ In rheumatoid arthritis (RA), destruction of bones may contribute to increased levels of serum Pyd.

Objectives: The purpose of this study was to compare the serum pyridinoline (Pyd) levels between RA patients and healthy controls and to determine the correlation of serum Pyd levels with radiographic joint erosions.

Methods: This was a monocentric, cross sectional, case-control study which was conducted from June 2016 to February 2017 at the Universiti Kebangsaan Malaysia Medical Centre (UKMMC). Serum samples were obtained from 48 patients with RA and 48 healthy controls. The enzyme-linked immunosorbent assay (ELISA) method was used for quantitative analysis of serum Pyd. Besides, all the RA patients were assessed for joint damage based on Modified Sharp Score (MSS), disease activity based on the disease activity score in 28-joints (DAS 28) and functional capacity based on Health Assessment Questionnaires Disability Index (HAQ-DI).

Abstract AB0301 - Table 1. Correlation between serum pyridinoline and other clinical variables

\begin{tabular}{|l|c|c|c|}
\hline & \multicolumn{3}{|c|}{ Serum Pyridinoline } \\
\cline { 2 - 4 } & $r$ & $r^{2}$ & $P$ \\
\hline DAS 28 & -0.010 & 7.431 & 0.945 \\
\hline $\begin{array}{l}\text { Joint erosion } \\
\text { score }\end{array}$ & 0.285 & 0.086 & 0.049 \\
\hline JSN score & -0.076 & 7.560 & 0.605 \\
\hline Total MSS & -0.009 & 0.005 & 0.952 \\
\hline HAQ-DI & -0.186 & 0.051 & 0.205 \\
\hline
\end{tabular}

Results: The median serum Pyd levels was much higher among the RA patients (110.20 ng/mL [92.30-120.64]) compared to the controls $(98.22 \mathrm{ng} / \mathrm{mL}$ [85.54$111.41]) ; p<0.05$. RA patients with erosive disease had significantly higher serum 
Pyd levels $(p=0.024)$. There was a significant positive correlation between serum Pyd levels and joint erosion score $(r=0.285, p=0.049)$. The serum Pyd levels had no demonstrable association with disease activity or functional capacity. Neither steroid nor biologic therapy influenced the levels of serum Pyd.

Conclusions: RA patients had significantly higher levels of serum Pyd compared to healthy controls. The serum Pyd levels had significant correlation with radiographic joint erosions which reflected disease damage.

\section{REFERENCES:}

[1] Nemoto R, Nakamura I, Nishijima Y, Shiobara K, Shimizu M, Takehara T, et al. Serum pyridinoline crosslinks as markers of tumour-induced bone resorption. Br J Urol. 1997;80:274-80.

[2] Plant MJ, Williams AL, O'Sullivan MM, Lewis PA, Coles EC, Jessop JD. Relationship between time-integrated C-reactive protein levels and radiologic progression in patients with rheumatoid arthritis. Arthritis Rheum 2000;43:1473-7.

Acknowledgements: The authors would like to thank the Research Committee of UKMMC for funding this research.

Disclosure of Interest: None declared

DOI: 10.1136/annrheumdis-2018-eular.2378

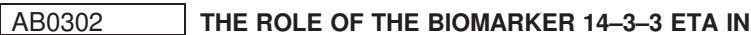 RHEUMATOID ARTHRITIS: A REVIEW}

\section{S. Kilborn, M. Bukhari. Medicine, Lancaster University, Lancaster, UK}

Background: Biomarkers are of much interest in rheumatoid arthritis (RA). Valid, reliable and convenient biomarkers, to detect early disease, predict severity and monitor treatment response are essential to achieving optimal outcomes. Several biomarkers have been suggested but are largely not validated. Validated measures of rheumatoid factor(RF), citrullination antibodies(ACPA), C-reactive protein (CRP) and erythrocyte sedimentation rate(ESR) do not provide a complete picture. $14-3-3 \eta$, a protein from a family of highly conserved regulatory molecules, has promising data as a novel RA biomarker and is the focus of this review.

Objectives: This review aimed to identify the literature characterising $14-3-3 \eta$ and its utility in RA.

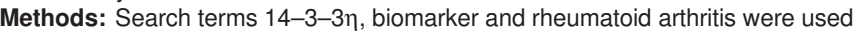
in Pubmed, Web of Science and Embase databases and reference lists of relevant papers were scanned. Inclusion criteria were confirmed RA, 14-3-3n and English language.

Results: Seven key papers were identified on $14-3-3 \eta$ proteins ${ }^{1-6}$ and one on

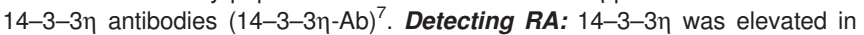
patients with RA compared to healthy controls ${ }^{2,4}$ and patients with other diseases $(p<0.001)^{4}$. Being positive for $14-3-3 \eta(>0.19 \mathrm{ng} / \mathrm{mL})$ showed sensitivity and specificity of $63.3 \%$ and $92.6 \%{ }^{4}$ to detect RA, increasing to $91.7 \%$ and $99.6 \%$, respectively when an ROC-determined optimal cut-off of $0.879 \mathrm{ng} / \mathrm{mL}$ was used ${ }^{2}$. When combined with current markers RF \pm ACPA the detection capacity for early RA increased to $78 \%$ and for established RA to $96 \%$, compared to $72 \%$ and $88 \%{ }^{4}$, respectively for RF $\pm A C P A$ alone. Including the $14-3-3 \eta-A b$ further

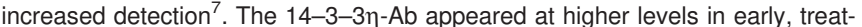
ment naïve RA, while no difference was seen in established RA compared to con-

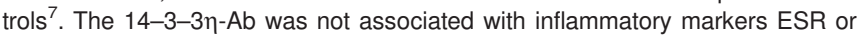
$\mathrm{CRP}^{7}$. Although higher levels of the $14-3-3 \eta$ protein were detected in early RA $(\mathrm{p}<0.05)$, rate of detection was higher in established $\mathrm{RA}^{2}$. Predicting disease severity: Baseline $14-3-3 \eta$ status was associated with increased disease severity ${ }^{1,2,3,4,5}$, higher median DAS (6.3 vs $\left.5.7, p=0.026\right)$ and HAQ scores ( 1.9 vs 1.0, $p=0.001)^{4}$. Significant associations with baseline DAS28-ESR, CDAI and SDAI $(p<0.045-p<0.001)$ were also reported ${ }^{3}$. Physical symptoms are closely related to $14-3-3 \eta$ levels $^{2}$; patients achieving DAS28-ESR-defined remission had significantly lower levels than non-remitters ${ }^{3}$. Radiographic progression was significantly associated with higher $14-3-3 \eta^{15}, \mathrm{OR}=6.2(95 \% \mathrm{Cl} 1.3$ to 30.2$)$ in early $\mathrm{RA}$ and $2.5(95 \% \mathrm{Cl} 1.0$ to 1.4$)$ in established $\mathrm{RA}^{5}$. Conflicting results on associations with existing markers ESR, CRP, RF, and ACPA have been reported ${ }^{1,2,3,4,5,6}$. Treatment response: $14-3-3 \eta$ levels are dynamic with changing disease activity ${ }^{1,3}$. Also, pre-treatment $14-3-3 \eta$ levels were an independent predictor of response to some therapies ${ }^{3}$.

Conclusions: $14-3-3 \eta$ protein and $\mathrm{Ab}$ are promising biomarkers in RA diagnosis, disease severity and response to treatment. Future research characterising the protein in RA and its relationship with validated biomarkers and composite

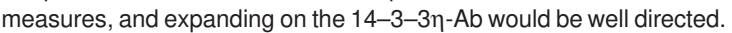

\section{REFERENCES:}

[1] Arthritis Res Ther. 2016;18:37

[2] Clin Rheumatol. 2017;36(11):2581-87

[3] Arthritis Res Ther. 2015;17:280.

[4] J Rheumatol. 2014;41(11):2104-13.
[5] Arthritis Res Ther. 2014;16:R99.

[6] Arthritis Res Ther. 2016;18:76

[7] J Rheumatol. 2015;42(9):1587-94

Disclosure of Interest: None declared DOI: 10.1136/annrheumdis-2018-eular.6614

\section{AB0303 ULTRASOUND ASPECT OF POSTERIOR TIBIAL TENDON IN RHEUMATOID ARTHRITIS}

S. Afilal ${ }^{1}$, H. rkain ${ }^{1}$, S. fellous ${ }^{1}$, L. tahiri ${ }^{1}$, N. alami ${ }^{1}$, R. Guieu ${ }^{2}$, Y. Jammes ${ }^{3}$, F. Allali' ${ }^{1}$ N. Hajjaj-Hassouni ${ }^{4} .{ }^{1}$ Department of Rheumatology B, El Ayachi Hospital, Faculty of Medicine and Pharmacy of Rabat, Mohammed V University, Rabat, Morocco., Rabat, Morocco; ${ }^{2}$ UMR MD2 Faculty of Medicine, Aix-Marseille University, Marseille, France: ${ }^{3}$ UMR MD2 Faculty of Medicine, Aix-Marseille University, Marseille, France., Marseille, France; ${ }^{4}$ Center for Pedagogical Innovation, Mohammed VI University of Health Sciences, Casablanca, Morocco, casablanca, Morocco

Background: Posterior tibial tendon involvement is common in rheumatoid arthritis. Ultrasound has an important place in the examination of this tendon.

Objectives: Evaluate the prevalence of ultrasound signs of posterior tibial tendon involvement in rhumatoid arthritis.

Methods: This is a cross-sectional study that included fourteen consecutive patients (100\% female, mean age 55.3 years) with rhumatoid arthritis (median duration of progression of 13.5 years, mean specialised care of 2.1 years). A grey and Doppler ultrasound study was performed on affected feet, looking for effusion, thickening or corporal thinning, hypoechoic aspect, fissures, and Doppler activity in the posterior tibial tendon.

Results: 28 feet were studied with ultrasound evaluation of the posterior tibial tendon. Figure 1 illustrates the prevalence of the pathological aspects of the posterior tibial found on ultrasound examination.

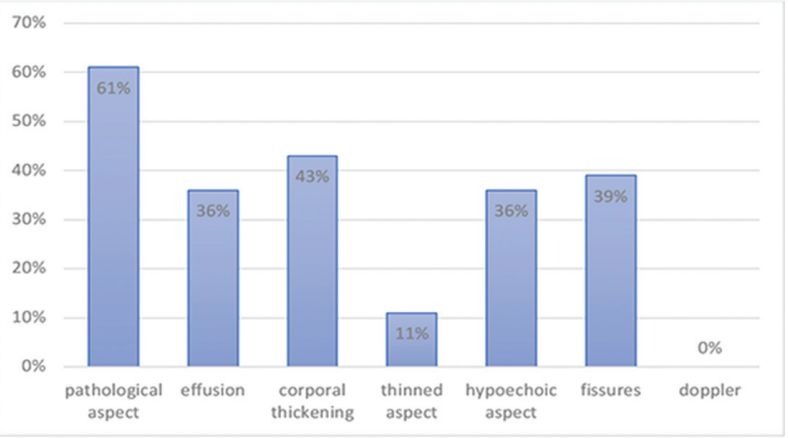

Abstract $\mathrm{AB0303} \mathrm{-} \mathrm{Figure} \mathrm{1.} \mathrm{Ultrasound} \mathrm{aspects} \mathrm{of} \mathrm{the} \mathrm{posterior} \mathrm{tibial} \mathrm{tendon} \mathrm{in} \mathrm{patients}$ RA

Conclusions: This study illustrates the different pathological aspects of the posterior tibial tendon. It highlights the high prevalence of this tendinopathy in the rheumatoid foot. Ultrasound allows accurate assessment of this tendon in RA patients.

A large-scale study compared with a control group is necessary to better interpret and complete these preliminary results.

Disclosure of Interest: None declared

DOI: 10.1136/annrheumdis-2018-eular.5925

\section{AB0304 ARTHRITIS BY A RHEUMATOLOGIST IS ASSOCIATED WITH AN ALTERATION OF THE FUNCTION OF THE FOOT}

S. Afilal ${ }^{1}$, H. rkain ${ }^{1}$, S. fellous ${ }^{1}$, L. tahiri ${ }^{1}$, N. alami ${ }^{1}$, R. guieu ${ }^{2}$, Y. jammes ${ }^{2}$, F. allali $^{1}$, N. Hajjaj-Hassouni ${ }^{3} .{ }^{1}$ Department of Rheumatology B, El Ayachi Hospital., Faculty of Medicine and Pharmacy of Rabat, Mohammed V University, Rabat, Morocco., Rabat, Morocco; ${ }^{2}$ UMR MD2 Faculty of Medicine, Aix-Marseille University, marseille, France; ${ }^{3}$ Center for Pedagogical Innovation, Mohammed VI University of Health Sciences, Casablanca, Morocco., casablanca, Morocco

Background: Impairment of foot function is known in rheumatoid arthritis Objectives: Evaluate the functional status of the foot in patients with RA and look for factors associated with impaired foot function. 